\begin{tabular}{|c|c|c|}
\hline BIODIK & $\begin{array}{c}\text { BIODIK: Jurnal IImiah Pendidikan Biologi } \\
\text { ISSN 2580-0922 (online), ISSN 2460-2612 (print) } \\
\text { Volume 6, Nomor 04, Tahun 2020, Hal. 507-518 } \\
\text { Available online at: } \\
\text { https://online-journal.unja.ac.id/biodik }\end{array}$ & BIODIK \\
\hline
\end{tabular}

Research Article

OPEN ACCESS

\title{
Rekonstruksi dan Pengembangan Lembar Kerja Siswa pada Materi Plantae Submateri Spermatophyta dengan Pendekatan Keterampilan Proses
}

\section{(Reconstruction and Development of Student Worksheets on the Spermatophyta Submaterial Plantae Material with a Process Skills Approach)}

Ria Anita Ekselsa, Bambang Supriatno, Sri Anggraeni

Universitas Pendidikan Indonesia

Jl. Dr. Stiabudi No. 229, Bandung, Indonesia

Coressponding Author: riaanita2808@gmail.com

\begin{tabular}{|c|c|}
\hline Informasi Artikel & ABSTRACT \\
\hline $\begin{array}{l}\text { Submit: } 04-06-2020 \\
\text { Diterima: } 17-08-2020 \\
\text { Dipublikasikan: } 18-12-2020\end{array}$ & $\begin{array}{l}\text { Student Worksheet (LKS) is a guide and support for practicum in learning science / } \\
\text { science. In biology lessons, especially the material of Spermatophyta Submaterial } \\
\text { Plantae, currently it is not optimal. This can be seen from the content of the } \\
\text { worksheets that do not cover all the competencies that have been formulated in the } \\
\text { curriculum. Therefore, this study aims to reconstruct the worksheets on the } \\
\text { Spermatophyta submaterial Plantae. The research method used the ANCOR } \\
\text { (Analysis-Try-Reconstruction) approach. At the analysis stage, the LKS analysis } \\
\text { process is based on conceptual, practical, and knowledge construction aspects. Then } \\
\text { at the trial stage carried out without changes in tools, materials and procedures. } \\
\text { Furthermore, the LKS reconstruction refers to the vee diagram and applies a process } \\
\text { skills approach. The results showed that there were problems with the } \\
\text { Spermatophyta LKS in the field, including the contents of the worksheets that did not } \\
\text { cover all the competencies expected by the curriculum, the work steps were less } \\
\text { relevant and the discussion questions did not support the student's knowledge } \\
\text { construction process. The results of the reconstruction worksheets were added by } \\
\text { phenetic analysis activities to align with the basic competencies that had been } \\
\text { formulated. These reconstruction worksheets can become alternative worksheets in } \\
\text { accordance with curriculum standards and representatives for all time. } \\
\text { Keywords: practicum, student worksheets, process skills, spermatophyta }\end{array}$ \\
\hline Penerbit & ABSTRAK \\
\hline $\begin{array}{l}\text { Program Studi Pendidikan } \\
\text { Biologi, Fakultas Keguruan dan } \\
\text { Ilmu Pendidikan, Universitas } \\
\text { Jambi-Indonesia }\end{array}$ & $\begin{array}{l}\text { Lembar Kerja Siswa (LKS) merupakan penuntun dan penunjang praktikum dalam } \\
\text { pembelajaran sains I IPA. Pada pelajaran Biologi khususnya materi Plantae } \\
\text { submateri Spermatophyta saat ini belum optimal. Hal itu dapat dilihat dari isi LKS } \\
\text { tidak mencakup semua kompetensi yang telah dirumuskan pada kurikulum. Oleh } \\
\text { karena itu, penelitian ini bertujuan untuk rekonstruksi LKS pada materi Plantae } \\
\text { submateri Spermatophyta. Adapun metode penelitian ini menggunakan pendekatan } \\
\text { ANCOR (Analisis-Coba-Rekonstruksi). Pada tahap analisis, proses analisis LKS } \\
\text { berdasarkan aspek konseptual, praktikal, dan konstruksi pengetahuan. Kemudian } \\
\text { pada tahap uji coba dilakukan tanpa perubahan alat, bahan dan prosedur. } \\
\text { Selanjutnya, rekonstruksi LKS mengacu pada diagram vee dan menerapkan } \\
\text { pendekatan keterampilan proses. Hasil penelitian menunjukkan bahwa terdapat } \\
\text { permasalahan pada LKS Spermatophyta yang ada di lapangan, diantaranya isi LKS } \\
\text { tidak mencakup semua kompetensi yang diharapkan kurikulum, langkah kerja kurang } \\
\text { relevan dan pertanyaan diskusi belum menunjang proses konstruksi pengetahuan } \\
\text { siswa. Hasil LKS rekonstruksi ada penambahan kegiatan analisis fenetik untuk } \\
\text { menyelaraskan dengan kompetensi dasar yang telah dirumuskan. LKS rekonstruksi } \\
\text { ini dapat menjadi LKS alternatif yang sesuai dengan standar kurikulum dan } \\
\text { representative untuk sepanjang masa. } \\
\text { Katakunci: praktikum, lembar kerja siswa, keterampilan proses, spermatophyta }\end{array}$ \\
\hline
\end{tabular}




\section{(1) (2)(2)

This BIODIK : Jurnal IImiah Pendidikan Biologi is licensed under a CC BY-NC-SA (Creative Commons Attribution-ShareAlike 4.0 International License)

\section{PENDAHULUAN}

Pembelajaran sains yang efektif harus memperhatikan dua hal, yaitu hakekat bagaimana siswa belajar dan hakekat materi yang diajarkan (Romlah \& Adisedjaja, 2009). Oleh karena itu, guru harus memperhatikan kompetensi yang harus dikuasai siswa, serta objek atau materi yang harus dipelajari, sehingga kegiatan pembelajaran yang dilaksanakan benar-benar mendukung tercapainya kompetensi / tujuan belajar. Penting bagi guru untuk memahami hakikat sains, dimana dalam pembelajaran sains harus mencakup sains sebagai proses, produk dan sikap ilmiah (Oviana, 2015), (N. Y. Rustaman, 2017), (Romlah \& Adisedjaja, 2009). Pembelajaran sains saat ini masih cenderung menyampaikan konten berupa konsep, prinsip, hukum atau produk sains kepada siswa (Oviana, 2015), (Romlah \& Adisedjaja, 2009). Pembelajaran kurang melatih siswa bagaimana proses yang harus dilakukan agar dapat memperoleh produk sains dan sikap seperti apa yang harus dimiliki agar dapat menghasilkan produk yang valid dan objektif (Oviana, 2015). Produk sains yang terdiri dari fakta, konsep, prinsip, hukum, teori dapat dicapai melalui penggunaan proses sains, yaitu melalui metode-metode sains atau metode ilmiah (scientific methods), bekerja ilmiah (scientific inquiry). Untuk dapat bekerja ilmiah diperlukan keterampilan proses sebagai keterampilan dasar yang harus dikembangkan atau dilatihkan sebelum seseorang mampu menggunakan metode ilmiah (N. Rustaman, 2011).

Kegiatan (science activities) harus membekali siswa untuk mengembangkan operasi mereka menjadi sesuatu yang bermakna sekaligus melatihkan keterampilanketerampilan saintifik (ilmiah) (N. Y. Rustaman, 2017). Kegiatan praktikum merupakan cara yang sesuai untuk memenuhi tuntutan belajar sains berdasarkan hakekat sains dan melatihkan keterampilan proses sains dan inkuiri ilmiah (Romlah \& Adisedjaja, 2009). Keterampilan proses melibatkan keterampilan-keterampilan kognitif atau intelektual, manual dan sosial sehingga pembelajaran sains akan lebih bermakna. Dengan demikian, dengan pendekatan keterampilan proses memungkinkan siswa mempelajari bahkan menemukan konsep yang menjadi tujuan belajar sains dan sekaligus mengembangkan keterampilan-keterampilan dasar sains, sikap ilmiah dan sikap kritis (Adisendjaja, 2008).

Praktikum merupakan kegiatan yang penting dalam pembelajaran sains / IPA. Praktikum adalah kegiatan pengamatan atau memanipulasi benda di laboratorium atau diluar laboratorium. Praktikum memiliki peran sentral dalam meningkatkan pengetahuan ilmiah siswa dan mendorong rasa ingin tahu siswa. Dalam praktikum

\section{Ekselsa, dkk}


siswa belajar mengidentifikasi objek dan fenomena, belajar fakta, belajar konsep, belajar menghubungkan ide dan belajar teori/model (Millar, 2004). Efektivitas praktikum dapat dilihat dari segi : (1). prosedur kegiatan, yaitu terkait dengan apa yang dikerjakan oleh siswa, dan (2). apa yang dipelajari siswa, hal ini berarti terkait dengan objek atau materi yang harus dipelajari (Abrahams \& Millar, 2008). Dengan demikian, penting bagi guru untuk dapat menyelaraskan kegiatan siswa sesuai dengan tujuan pembelajarannya atau kompetensi yang harus dicapai yang telah dirumuskan dalam kurikulum. Kenyataan yang ada di lapangan, LKS dari tahun ke tahun tidak berubah mengikuti perubahan kurikulum.

Menurut Rustaman, belajar IPA dengan praktikum tidak secara otomatis dapat meningkatkan kemampuan dasar bekerja ilmiah. Hal ini disebabkan karena sebagian besar pembelajaran IPA dengan praktikum hanya bersifat verifikatif dan ditujukan untuk menunjang penguasaan konsep, bukan untuk pengembangan keterampilan dasar bereksperimen (keterampilan proses sains) (N. Y. Rustaman, 2005). Keterampilan proses ini meliputi keterampilan mengamati, mengajukan hipotesis, menggunakan alat dan bahan, mengajukan pertanyaan, menggolongkan dan menafsirkan data, serta mengkomunikasikan hasil temuan secara lisan atau tertulis. Berdasarkan kenyataan yang ada di lapangan, umumnya LKS Spermatophyta lebih bersifat verifikatif untuk menunjang penguasaan konsep. Praktikum diberikan setelah siswa mempelajari keseluruhan materi atau konsep. Bahan praktikum juga umumnya mengikuti yang sudah ada pada buku teks sebagai contoh, bahan disertakan dengan nama ilmiah sehingga siswa dapat mencari tahu taksonominya diluar praktikum. Hal ini tidak mendukung siswa dalam mengembangkan keterampilan dan kemampuan berfikir siswa. Oleh karena itu perlu dilakukan pengembangan kegiatan praktikum sehingga siswa dapat berbuat seperti seorang ilmuwan yang melakukan eksperimen yang dapat melatih siswa bekerja secara ilmiah dengan mengembangkan keterampilan proses sains serta dapat mengembangkan kemampuan berfikir. Dengan demikian siswa diarahkan untuk menemukan konsep dan membangun pengetahuannya sendiri, sehingga dalam proses pembelajarannya siswa lebih berperan aktif.

Praktikum Spermatophyta membantu siswa untuk meningkatkan keterampilan proses sains seperti keterampilan mengamati karakter morfologi dan menggolongkannya sehingga membentuk pengetahuan siswa mengenai konsep tumbuhan berbiji. Praktikum ini penting untuk kemampuan siswa melakukan identifikasi tumbuhan dan mengklasifikasikannya. Namun berdasarkan hasil analisis, praktikum yang ada kurang sesuai dengan tujuan pembelajaran atau kompetensi yang diharapkan, kurang mendorong keterampilan proses siswa dan kurang mengkonstruk pengetahuan siswa. LKS sebagai petunjuk praktikum kurang optimal, karena metode kurang relevan, tidak ada proses interpretasi data, pertanyaan yang muncul tidak menanyakan objek atau peristiwa yang diamati siswa. Pertanyaan 
diskusi tidak produktif karena siswa dapat menjawab pertanyaan tanpa melakukan kegiatan praktikum dan tidak terstruktur mengkonstruksi pengetahuan siswa. Hal tersebut menjadikan kegiatan praktikum dirasa kurang bermakna bagi siswa. Menurut Rustaman, belajar menjadi bermakna bagi siswa apabila mereka mendapat kesempatan untuk mengajukan pertanyaan, melaksanakan penyelidikan, mengumpulkan data, membuat kesimpulan dan berdiskusi (Rustaman, 2005). Dari hasil penelitian Supriatno juga menyatakan LKS yang ada di lapangan memiliki banyak kelemahan baik dari struktur, prosedur maupun keterlaksanaannya. Hal ini karena LKS yang ada di lapangan tidak diadaptasi sesuai levelnya atau direkonstruksi bila terjadi kesalahan (Supriatno, 2013).

Diagram vee dapat membantu guru dalam membuat LKS agar kegiatan praktikum menjadi bermakna (Wahidah et al., 2018). Diagram vee membantu menemukan makna bahwa pengetahuan berasal dari kejadian / objek permasalahan yang diamati. Komponen-komponen dalam diagram vee dikelompokkan menjadi dua bagian, sisi konseptual dan sisi metodologikal. Sisi konseptual meliputi konsep, prinsip, teori, dan filosofi. Sedangkan sisi metodologikal meliputi pencatatan event, transformasi data, interpretasi, dan perolehan pengetahuan (knowledge claim) (Novak, Joseph D.; Ridley, 1987).

Dengan demikian, perlu dilakukan analisis terhadap LKS Spermatophyta yang sudah ada kemudian melakukan rekonstruksi LKS agar representatif dan lebih efektif sebagai sains activity. Rekonstruksi LKS dengan menerapkan pendekatan keterampilan proses dan juga mengacu pada diagram vee. LKS rekonstruksi ini diharapkan dapat melatih siswa bekerja secara ilmiah dan dapat mengembangkan kemampuan berpikir siswa.

\section{METODE PENELITIAN}

Metode yang digunakan adalah metode analisis deskriptif kualitatif. Penelitian ini menerapkan pendekatan ANCOR (Analisis-Coba-Rekonstruksi). Sampel yang dianalisis adalah LKS materi Plantae submateri Spermatophyta. Jumlah sampel sebanyak 7 LKS, diantaranya 3 LKS pada KTSP, 3 LKS pada kurikulum 2013, dan 1 LKS yang dibuat sendiri oleh guru. Instrument yang digunakan adalah instrument analisis konseptual, praktikal, dan konstruksi pengetahuan. Pertama, analisis dilakukan dengan membaca LKS secara konseptual dengan melihat aspek kesesuaian dengan kurikulum dan aspek konten / materi. Selanjutnya, analisis praktikal dengan melihat aspek prosedural. Peneliti melakukan uji coba LKS tanpa perubahan alat, bahan dan prosedur. Selanjutnya, analisis konstruksi pengetahuan dengan melihat pertanyaan diskusi, interpretasi data, dan penarikan kesimpulan. Dari hasil analisis dan uji coba, selanjutnya peneliti melakukan rekonstruksi LKS disertai dengan studi literatur. Rekonstruksi LKS dengan menerapkan pendekatan

\section{Ekselsa, dkk}


keterampilan proses dan mengacu pada diagram vee. Peneliti juga menguji keterbacaan dan keterlaksanaan kegiatan pada LKS hasil rekonstruksi.

\section{HASIL DAN PEMBAHASAN}

\section{Hasil Analisis Konseptual dan Konstruksi Pengetahuan}

Berdasarkan hasil analisis kurikulum, kompetensi dasar yang harus dimiliki siswa kelas $X$ pada materi Plantae submateri Spermatophyta adalah kompetensi pengetahuan (KD 3.8) yaitu siswa mampu mengelompokkan tumbuhan ke dalam divisio berdasarkan ciri-ciri umum, serta mengaitkan peranannya dalam kehidupan, dan kompetensi keterampilan (KD 4.8) yaitu menyajikan laporan hasil pengamatan dan analisis fenetik dan filogenetik tumbuhan serta peranannya dalam kehidupan. Dari 7 LKS yang dianalisis, 2 LKS pada kurikulum 2013, kontennya tidak sesuai dengan KD 3.8. 5 LKS lain sesuai namun satu diantaranya (LKS pada KTSP) kontennya kurang lengkap karena hanya mengamati perbedaan monokotil dan dikotil. Pengelompokkan tumbuhan ke dalam divisio spermatophyta adalah pembelajaran mengenai perbedaan antara subdivisi Gymnospermae dan Angiospermae, serta mengelompokkan Angiospermae menjadi kelas dikotil dan monokotil. Selain itu, peneliti juga menemukan bahwa pada 7 sampel LKS yang dianalisis tidak mencantumkan kompetensi keterampilan (KD 4.8). Dengan demikian, ada kegiatan yang kurang untuk mendukung keterampilan siswa. Keterampilan yang ingin dicapai dalam materi Spermatophyta ini adalah siswa dapat mengamati ciri morfologi, menyajikan data hasil pengamatan, mengelompokkan serta melakukan analisis fenetik dan filogenetik tumbuhan. Oleh karena itu, menurut peneliti praktikum Spermatophyta yang sudah ada belum sesuai dengan tujuan pencapaian kompetensi yang diharapkan dan perlu adanya rekonstruksi dengan menambahkan kegiatan siswa untuk mencapai kompetensi pada KD 4.8.

Katriani menjelaskan bahwa salah satu tujuan penyusunan LKPD adalah memperkuat dan menunjang tujuan pembelajaran dan ketercapaian indikator serta kompetensi dasar dan kompetensi inti yang sesuai dengan kurikulum yang berlaku. Metode dalam kegiatan praktikum juga harus dapat meningkatkan motivasi siswa dan mengembangkan kemampuan siswa dalam memecahkan masalah (Katriani, 2014). Oleh karena itu, diharapkan dengan penggunaan analisis fenetik dalam LKS Spermatophyta dapat meningkatkan motivasi, mendorong rasa ingin tahu siswa dan mengembangkan keterampilan memecahkan masalah dan berpikir kritis. Sejalan dengan penelitian yang telah dilakukan sebelumnya bahwa pendekatan fenetik memberikan pengaruh positif terhadap penguasaan konsep dan penalaran siswa, meningkatkan motivasi, merangsang siswa lebih aktif, memunculkan keingintahuan yang besar, dan meningkatkan keterampilan komunikasi siswa (Purwanto, 2016), (Octavia et al., 2010), (Oktaviani \& Hidayat, 2015), (Astuti, 2018). 
Satu LKS yang dibuat sendiri oleh guru dengan mengacu kepada kurikulum 2013, ditemukan bahwa ada ketidaksesuaian tujuan dengan langkah kerja dan ketidaksesuaian kegiatan dengan tingkat kognitif siswa. Kegiatannya tidak mengkonstruksi pengetahuan siswa, pertanyaan dan tabel yang disiapkan dapat diisi oleh siswa tanpa melakukan praktikum. Tidak ada kegiatan interpretasi data, dan tidak ada kegiatan analisis untuk menghubungkan konsep-konsep dari fakta yang ditemukan. Oleh karena itu, kegiatan praktikum dirasa kurang efektif dan kurang bermakna bagi siswa. Millar menjelaskan bahwa karakteristik dari praktikum yang efektif adalah tujuan pembelajarannya jelas, merangsang siswa untuk berpikir, serta mendorong siswa membuat hubungan antar dua ranah pengetahuan (Millar, 2004). Akibat dari kegiatan praktikum yang tidak efektif maka kegiatan tersebut tidak memberikan kontribusi berarti terhadap penguatan pemahaman atau untuk membantu mengkonstruksi pengetahuan baru terhadap siswa yang sedang belajar (Supriatno, 2013).

Berdasarkan analisis LKS dan wawancara dengan guru, umumnya praktikum dilakukan ketika konsep sudah diberikan, jadi praktikum tersebut sifatnya verifikasi untuk memperkuat pengetahuan yang sudah ada. Praktikum yang bersifat verifikasi harus mencantumkan dasar teori pada LKS. Namun, pada semua LKS tidak ada dasar teori. Dasar teori harus mengandung konsep dasar dan prinsip dimana konsep dasar adalah ide yang mengarahkan kepada aktivitas penyelidikan (apa yang harus diselidiki siswa) dan prinsip mengarahkan siswa untuk bagaimana objek dan peristiwa diamati (Hindriana, 2020). Praktikum yang bersifat verifikasi ini menurut peneliti juga menjadi suatu kelemahan dan kurang mendorong siswa untuk memiliki rasa keingintahuan yang lebih besar. Hal ini juga sejalan dengan analisis terhadap desain LKS Spermatophyta yang dilakukan oleh Hidayati bahwa karakteristik LKS pada umumnya kurang membantu mengembangkan keterampilan dan kemampuan berfikir siswa (Hidayati, 2014).

Dari hasil analisis konstruksi pengetahuan, pertanyaan diskusi pada 2 LKS dapat dijawab tanpa melakukan praktikum contohnya menanyakan skema daur hidup Gmynospermae dan Angiospermae. Kemudian sebanyak 4 LKS tidak menanyakan karakter fakta yang muncul. Tiga LKS tidak menggunakan fakta untuk mengkonstruksi konsep dan tidak ada proses interpretasi data. Tidak ada pertanyaan terkait prinsip pada semua LKS, dan 2 LKS tidak ada pertanyaan terkait analisis. Satu LKS yang dibuat oleh guru tidak mengarahkan siswa menarik kesimpulan dan knowledge claim, serta pencatatan data dalam tabel memungkinkan siswa mencari jawaban tanpa melakukan praktikum, sehingga kegiatan dirasa kurang bermakna. Dengan demikian dari 5 LKS yang sesuai dengan KD 3.8, hanya 1 LKS pada kurikulum 2013 yang sudah sesuai mengkonstruksi pengetahuan siswa. Dua LKS pada KTSP, proses siswa mengkonstruk pengetahuan dari kegiatan praktikum masih kurang. Hal ini karena proses penarikan kesimpulan sampai dengan mendapatkan

\section{Ekselsa, dkk}


knowledge claim masih lemah karena pertanyaan yang belum terstuktur. Dua LKS lainnya (KTSP \& LKS dibuat oleh guru) tidak mengkonstruksi pengetahuan siswa. Hal ini karena pencatatan dalam tabel yang tidak relevan serta pertanyaan dapat dijawab tanpa melakukan praktikum dan bersifat teoritis. Menurut Laelasari \& Supriatno, pertanyaan digunakan untuk mengukur ketercapaian proses dan tujuan, menuntun siswa untuk memahami konsep yang dipelajari dan mengarahkan siswa untuk membuat suatu kesimpulan yang tepat (Laelasari \& Supriatno, 2018).

\section{Hasil Uji Coba (Analisis Praktikal)}

Berdasarkan analisis praktikal dari 5 LKS yang sesuai dengan KD 3.8, sebanyak 2 LKS memiliki langkah kerja yang tidak relevan sehingga membuat siswa bingung dalam mengerjakan kegiatan. Langkah kerja yang tidak relevan menyebabkan siswa tidak menemukan karakteristik dari objek. Tiga LKS lainnya, langkah kerja relevan namun pada beberapa tahapan kurang detail dan kurang terstruktur. Setelah peneliti mencoba melakukan pengamatan terhadap beberapa tumbuhan, peneliti menemukan bahwa terkadang sulit untuk mendeskripsikan fakta yang ada. Oleh karena itu, diperlukan dasar teori dan petunjuk pengamatan berupa gambar agar siswa tidak bingung dalam proses pengamatannya. Sebagai contoh, untuk karakter daun, seperti apa pertulangan daun yang menjari, menyirip, melengkung, dan sejajar. Dengan demikian, LKS sebaiknya dilengkapi tabel yang berisi karakter dan ciri yang teramati sehingga siswa hanya mencentang ciri yang sesuai. Masih ada hambatan yang dirasakan untuk menghadirkan objek/fenomena, sehingga masih diperlukan perbaikan metode.

Langkah kerja pada LKS seharusnya memudahkan siswa melakukan pengamatan dengan mendeskripsikannya menggunakan langkah-langkah ilmiah agar siswa dapat menemukan konsep tentang pengelompokkan tumbuhan tersebut. Langkah kerja yang kurang terstruktur tidak mengarahkan siswa untuk memperoleh data yang benar (Laelasari \& Supriatno, 2018). LKS dengan langkah kerja yang terstruktur membantu siswa untuk mengkonstruk pemahamannya terhadap suatu pengetahuan. Siswa dapat menggunakan pengetahuan secara optimal jika mereka dapat membuat hubungan antara konsep-konsep dan menghasilkan pemahaman dari hubungan tersebut (Sedumedi, 2017).

\section{Hasil LKS Rekonstruksi}

Berdasarkan temuan dari hasil analisis konseptual, analisis praktikal dengan uji coba dan analisis konstruksi pengetahuan pada beberapa LKS, menjadi dasar bagi peneliti untuk melakukan rekonstruksi terhadap LKS Spermatophyta. LKS direkonstruksi dengan menerapkan pendekatan keterampilan proses dan mengacu pada diagram vee. 
Pada LKS rekonstruksi ini peneliti menambahkan kompetensi keterampilan yaitu KD 4.8 yang kemudian diturunkan menjadi indikator dan tujuan. Kompetensi tersebut adalah siswa mampu melakukan analisis fenetik dan filogenetik tumbuhan sehingga siswa mengetahui bagaimana dasar pengelompokkan tumbuhan. Dasar pengelompokkan tumbuhan tersebut menjadi knowledge claim yang diperoleh siswa melalui praktikum. Menurut Octavia, praktek penggunaan metode numerik-fenetik mampu mendapatkan konsep keanekaragaman hayati secara kuantitatif. Artinya bahwa hubungan kedekatan / kemiripan antar organisme yang diamati dapat diketahui persentase similaritas (kemiripan). Dengan demikian, meningkatkan inspirasi dan motivasi untuk mengembangkan keterampilan investigasi (Octavia et al., 2010).

Selain itu, peneliti merevisi indikator yang diturunkan dari KD 3.8 dan juga merevisi bahan. Bahan yang dicantumkan membebaskan siswa untuk membawa tanaman yang ditemukan disekitar lingkungannya. Hal ini agar siswa menjadi seperti ilmuwan yang melakukan penyelidikan. Diharapkan LKS ini dapat berlaku untuk sepanjang masa dan bisa mewakili standar kompetensi yaitu KD 3.8 dan KD 4.8 dalam satu LKS, serta bisa menjadi rujukan buku panduan siswa. Peneliti juga menambahkan landasan teori yang sesuai. Langkah kerja juga direvisi oleh peneliti menjadi langkah kerja yang relevan dan terstuktur agar mengarahkan siswa menemukan karakteristik dari objek yang diamati. Pada LKS ini juga ditambahkan pertanyaan diskusi yang mengarahkan siswa menjawab dengan melihat data hasil praktikum dan menarik kesimpulan dengan menjawab tujuan praktikum. Hal ini agar membantu siswa untuk mengkonstruk pengetahuannya dengan benar. Selanjutnya, peneliti menguji keterlaksanaan kegiatan dan mencoba kepada siswa untuk memahami keterbacaan prosedur LKS hasil rekonstruksi.

LKS yang dikembangkan terdiri dari 6 halaman. Adapun aspek yang dikembangkan meliputi aspek kurikulum yaitu kompetensi dasar, indikator \& tujuan, aspek materi, dan pertanyaan diskusi. Dari aspek kurikulum, ada penambahan kegiatan siswa dalam praktikum yang disesuaikan dengan KD 4.8. Kegiatan tersebut adalah melakukan analisis fenetik antar takson dan membuat fenogram untuk menganalisis filogenetik / kekerabatan antar takson.

Fenetik merupakan salah satu metode dalam sistematik yang menggambarkan hubungan kekerabatan berdasarkan penampakan morfologi atau menghasilkan klasifikasi yang merupakan kesamaan (similaritas) dari individu dengan pertimbangan berdasarkan satu set fenotip (karakter yang berhubungan dengan kenampakan). Tingkat kekerabatan dan kesamaan tergantung pada macam, sifat dasar dan interpretasi dari koefisien karakter yang digunakan (Agustina et al., 2014). Dalam analisis fenetik, kelompok-kelompok organisme dipetakan dalam bentuk diagram pohon (fenogram). Tingkat kepercayaan fenogram dapat ditentukan dari karakter yang dipilih, akurasi pengamatan terhadap karakter yang telah

\section{Ekselsa, dkk}


ditentukan, kerunutan langkah-langkah analisis fenetik yang telah ditetapkan, dan topologi fenogram (kesesuaian fenogram dengan konsep yang seharusnya). Jika kerunutan langkah-langkah analisis fenetik dapat dicapai dengan baik melalui LKS, siswa akan lebih mudah dan lancar dalam memahami konsep tumbuhan biji (Hidayat et al., 2012). Pembelajaran keanekaragaman tumbuhan biji dengan penugasan fenetik dapat meningkatkan penguasaan konsep dan membuat siswa terlibat aktif dalam pembelajaran (Hidayat et al., 2012). Hal yang sama dinyatakan Astuti bahwa kemampuan mengklasifikasi tumbuhan tingkat rendah pada siswa meningkat setelah diberikan pembelajaran menggunakan LKS yang memuat analisis fenetik (Astuti, 2018).

Terdapat lima langkah dalam melakukan analisis fenetik. Pertama, menyeleksi organisme yang akan dianalisis (disebut taksa), karakter dan ciri. Taksa bisa berupa divisi / filum, kelas, bangsa, family, marga, jenis, varitas, dll. Karakter biasanya meliputi hanya dua ciri, ada (diberi kode 1) dan tidak ada (diberi kode 0). Tetapi, karakter bisa memliki banyak ciri. Kedua, menentukan tingkat kesamaan antara pasangan taksa dengan menghitung koefisien kesamaan, yaitu hasil bagi antara jumlah karakter yang sama dengan total karakter yang digunakan. Ketiga, menyusun koefisien kesamaan dalam bentuk matriks kesamaan. Keempat, membuat klastering dengan mengidentifikasi pasangan taksa yang memiliki koefisien kesamaan tertinggi, selanjutnya disusun sampai pada pasangan taksa yang memiliki kesamaan terendah. Terakhir, merekonstruksi pohon kekerabatan fenetik (fenogram) berdasarkan klastering yang telah dilakukan (Hidayat, 2017).

Keterampilan proses sains yang diimplementasikan kedalam LKS terdiri dari keterampilan mengamati, mengajukan hipotesis, menggolongkan, menganalisis, melakukan interpretasi data dan menyimpulkan. Keterampilan mengamati diimplementasikan pada saat kegiatan siswa mengamati karakter / ciri morfologi dari tumbuhan. Keterampilan mengajukan hipotesis dilatihkan ketika siswa diminta membuat hipotesis takson mana yang memiliki hubungan kekerabatan yang dekat. Keterampilan menggolongkan dilatihkan pada kegiatan siswa mengelompokkan tumbuhan biji berdasarkan kesamaan karakter morfologinya dan berdasarkan indeks similaritas. Keterampilan menganalisis dan menyimpulkan dilatihkan pada kegiatan siswa menjawab pertanyaan-pertanyaan diskusi berdasarkan hasil pengamatan. Keterampilan melakukan interpretasi data dilatihkan ketika siswa membaca dan menginterpretasi tabel dan fenogram yang dihasilkan. Dengan demikian, penggunaan metode fenetik ini dapat menambah keterampilan proses siswa dimana ada proses siswa mengajukan hipotesis, menginterpretasi dan mengkomunikasikan hasil fenogram. Keterampilan mengajukan hipotesis ini tidak ditemukan pada semua LKS Spermatophyta yang dianalisis oleh peneliti.

LKS juga dikembangkan dengan mengacu pada diagram Vee. Diagram vee dapat membantu guru dalam membuat LKS agar kegiatan praktikum menjadi 
bermakna (Wahidah et al., 2018). LKS diawali dengan judul praktikum berupa focus question yang sesuai dengan tujuan pembelajaran dan kompetensi yang diharapkan dalam kurikulum. Langkah kerja direvisi lagi agar relevan dan terstruktur sehingga peristiwa utama atau objek dapat diidentifikasi. Kemudian ada dasar teori berisi konsep dasar dan prinsip. Pencatatan data dalam tabel juga diperbaiki agar lebih efektif. Selanjutnya pertanyaan diskusi juga diperbaiki dan dikembangkan lagi oleh peneliti. Pertanyaan berupa pertanyaan scaffolding atau terstruktur agar mengarahkan siswa membentuk klaim pengetahuan. Pertanyaan yang diajukan terkait dengan fakta / peristiwa yang muncul sehingga siswa melakukan interpretasi data, dan juga pertanyaan terkait prinsip. Pertanyaan dan klaim pengetahuan yang diperoleh diharapkan dapat menjawab focus question. Dengan demikian, dalam praktikum siswa diajak untuk lebih aktif, berpikir kritis dan mengembangkan keterampilan proses sains, sehingga kegiatan dirasa bermakna oleh siswa.

\section{KESIMPULAN}

Hasil analisis konseptual, praktikal dan konstruksi pengetahuan pada beberapa LKS Spermatophyta dapat disimpulkan bahwa LKS Spermatophyta tidak mencakup semua kompetensi yang diharapkan dalam kurikulum, langkah kerja kurang relevan dan pertanyaan diskusi belum menunjang proses konstruksi pengetahuan siswa.Temuan dari hasil analisis tersebut membuat peneliti merekonstruksi LKS. Adapun aspek yang direkonstruksi meliputi aspek kurikulum meliputi kompetensi dasar, indikator \& tujuan, aspek materi, dan pertanyaan diskusi. Pada LKS rekonstruksi ditambahkan kegiatan analisis fenetik untuk menyelaraskan dengan kompetensi dasar yang telah dirumuskan kurikulum. LKS rekonstruksi menerapkan pendekatan keterampilan proses dan mengacu pada diagram vee untuk mendukung aspek konstruksi pengetahuan. Keterampilan proses sains yang diimplementasikan kedalam LKS terdiri dari keterampilan mengamati, mengajukan hipotesis, menggolongkan, menganalisis, melakukan interpretasi data dan menyimpulkan. Diharapkan LKS rekonstruksi ini menjadi LKS alternatif yang sesuai dengan standar kurikulum dan representative untuk sepanjang masa, serta dapat menjadi rujukan untuk buku panduan siswa.

\section{DAFTAR PUSTAKA}

Abrahams, I., \& Millar, R. (2008). Does practical work really work? A study of the effectiveness of practical work as a teaching and learning method in school science. International Journal of Science Education, 1(1), 1-25. https://doi.org/10.1080/09500690701749305

Adisendjaja, Y. H. (2008). Analisis buku ajar biologi sma kelas $\mathrm{X}$ di kota bandung berdasarkan literasi sains. In BIO-UPI.

Agustina, S., Widodo, P., \& Hidayah, H. A. (2014). Analisis fenetik kultivar cabai

\section{Ekselsa, $d k k$}


besar Capsicum annuum L. dan cabai kecil Capsicum frutescens L. Scripta Biologica, 1(1), 117-125.

Astuti, E. (2018). Efektivitas lembar kerja siswa dalam mengklasifikasikan tumbuhan tingkat rendah melalui analisis fenetik. In Jurusan Pendidikan Biologi FPMIPA UPI. Universitas Pendidikan Indonesia.

Hidayat, T. (2017). Menggairahkan pembelajaran taksonomi di kelas menggunakan metode fenetik (Issue February).

Hidayat, T., Sutarno, N., \& Awaliyah, R. N. (2012). Pengaruh penugasan fenetik terhadap penguasaan konsep keanekaragaman tumbuhan biji. Jurnal Pengajaran Matematika Dan IImu Pengetahuan Alam, 17(2), 209. https://doi.org/10.18269/jpmipa.v17i2.247

Hidayati, S. M. (2014). Pengembangan lembar kerja siswa (LKS) spermatophyta berdasarkan pendekatan saintifik di SMA. Universitas Pendidikan Indonesia.

Hindriana, A. F. (2020). Pengembangan lembar kerja praktikum berbasis diagram vee guna memfasilitasi kegiatan laboratorium secara bermakna. Quagga: Jurnal $\begin{array}{llll}\text { Pendidikan Dan Biologi, } & \text { 62-68. }\end{array}$ https://doi.org/10.25134/quagga.v12i1.2331

Katriani, L. (2014). Pengembangan lembar kerja peserta didik (LKPD). In Jurusan Pendidikan Fisika FMIPA UNY.

Laelasari, I., \& Supriatno, B. (2018). Analisis komponen penyusun desain kegiatan laboratorium bioteknologi. Jurnal Bioedukatika, 6(2), 84-90.

Millar, R. (2004). The role of practical work in the teaching and learning of science (Issue October).

Novak, Joseph D.; Ridley, D. (1987). Assessing student learning in light of how students learn.

Octavia, B., Umniyatie, S., \& Rakhmawati, A. (2010). Aplikasi metode taksonomi numerik-fenetik untuk pengayaan materi keanekaragaman hayati di sekolah menengah atas.

Oktaviani, F., \& Hidayat, T. (2015). Profil keterampilan berkomunikasi siswa sma menggunakan metode fenetik dalam pembelajaran klasifikasi arthropoda. Jurnal Pengajaran Matematika Dan Ilmu Pengetahuan Alam, 15(1), 13. https://doi.org/10.18269/jpmipa.v15i1.288

Oviana, W. (2015). Pemahaman hakekat sains dan aplikasinya dalam proses pembelajaran sains. Prosiding Semminar Nasional Biotik 2015, 485-490.

Purwanto, C. E. (2016). Penerapan pendekatan fenetik dalam meningkatkan penguasaan konsep arthropoda dan penalaran siswa. Universitas Pendidikan Indonesia.

Romlah, O., \& Adisedjaja, Y. H. (2009). Peranan praktikum dalam mengembangkan keterampilan proses dan kerja laboratorium. In BIO-UPI.

Rustaman, N. (2011). Materi dan Pembelajaran IPA di SD. In Universitas Terbuka.

Rustaman, N. Y. (2005). Perkembangan penelitian pembelajaran berbasis inkuiri dalam pendidikan sains. In FPMIPA UPI.

Rustaman, N. Y. (2017). Mewujudkan sistem pembelajaran sains / biologi berorientasi pengembangan literasi peserta didik. Biologi, Pembelajaran, Dan Lingkungan Hidup Perspektif Interdisipliner, April, 1-8. http://researchreport.umm.ac.id/index.php 
Sedumedi, T. D. T. (2017). Practical work activities as a method of assessing learning in chemistry teaching. Eurasia Journal of Mathematics, Science and Technology Education, 13(6), 1765-1784.

Supriatno, B. (2013). Pengembangan program perkuliahan pengembangan praktikum biologi sekolah berbasis ANCORB untuk mengembangkan kemampuan merancang dan mengembangkan desain kegiatan laboratorium. In Universitas Pendidikan Indonesia. Universitas Pendidikan Indonesia.

Wahidah, N. S., Supriatno, B., \& Kusumastuti, M. N. (2018). Analisis Struktur dan Kemunculan Tingkat Kognitif pada Desain Kegiatan Laboratorium Materi Fotosintesis. Assimilation: Indonesian Journal of Biology Education, 1(2), 70. 